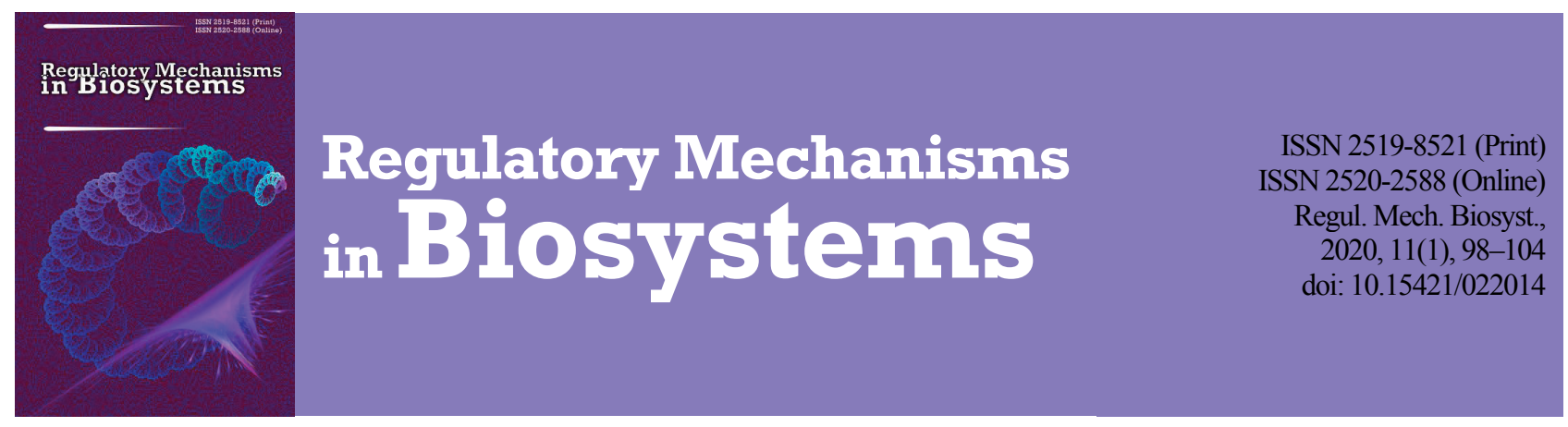

\title{
The intensity of ethylene release by soybean plants under the influence of fungicides in the early stages of legume-rhizobial symbiosis
}

\author{
T. P. Mamenko, S. Y. Kots, Y. O. Khomenko \\ Institute of Plant Physiology and Genetics, National Academy of Sciences of Ukraine, Kyiv, Ukraine
}

Article info

Received 24.12.2019

Received in revised form 21.01.2020

Accepted 22.02.2020

Institute of Plant Physiology and Genetics, National

Academy of Sciences of

Ukraine, Vasylkivska st.,

31/17, Kyiv, 03022, Ukraine.

Tel.: +38-050-964-17-89.

E-mail:t_mamenko@ukr.net

\begin{abstract}
Mamenko, T. P., Kots, S. Y., \& Khomenko, Y. O. (2020). The intensity of ethylene release by soybean plants under the influence of fungicides in the early stages of legume-rhizobial symbiosis. Regulatory Mechanisms in Biosystems, 11(1), 98-104. doi:10.15421/022014
\end{abstract}

The effect of pre-sowing treatment of soybean seeds with fungicides on the intensity of ethylene release, the processes of nodulation and nitrogen fixation in different symbiotic systems in the early stages of ontogenesis were investigated. The objects of the study were selected symbiotic systems formed with the participation of soybean (Glycine max (L.) Merr.) Diamond variety, strains Bradyrhizobium japonicum 634b (active, virulent) and 604k (inactive, highly virulent) and fungicides Maxim XL 035 PS (fludioxonil, $25 \mathrm{~g} / \mathrm{L}$, metalaxyl, $10 \mathrm{~g} / \mathrm{L}$ ), and Standak Top (fipronil, $250 \mathrm{~g} / \mathrm{L}$, thiophanate methyl, $225 \mathrm{~g} / \mathrm{L}$, piraclostrobin, $25 \mathrm{~g} / \mathrm{L}$ ). Before sowing, the seeds of soybean were treated with solutions of fungicides, calculated on the basis of one rate of expenditure of the active substance of each preparation indicated by the producer per ton of seed. One part of the seeds treated with fungicides was inoculated with rhizobium culture for $1 \mathrm{~h}$ (the titre of bacteria was $10^{7} \mathrm{cells} / \mathrm{mL}$ ). To conduct the research we used microbiological, physiological, biochemical methods, gas chromatography and spectrophotometry. It is found that, regardless of the effectiveness of soybean rhizobial symbiosis, the highest level of ethylene release by plants was observed in the stages of primordial leaf and first true leaf. This is due to the initial processes of nodulation - the laying of nodule primordia and the active formation of nodules on the roots of soybeans. The results show that with the participation of fungicides in different symbiotic systems, there are characteristic changes in phytohormone synthesis in the primordial leaf stage, when the nodule primordia are planted on the root system of plants. In particular, in the ineffective symbiotic system, the intensity of phytohormone release decreases, while in the effective symbiotic system it increases. At the same time, a decrease in the number of nodules on soybean roots inoculated with an inactive highly virulent rhizobia $604 \mathrm{k}$ strain due to the action of fungicides and an increase in their number in variants with co-treatment of fungicides and active virulent strain $634 \mathrm{~b}$ into the stage of the second true leaf were revealed. It was shown that despite a decrease in the mass of root nodules, there is an increase in their nitrogen-fixing activity in an effective symbiotic system with the participation of fungicides in the stage of the second true leaf. The highest intensity of ethylene release in both symbiotic systems was recorded in the stage of the first true leaf, which decreased in the stage of the second true leaf and was independent of the nature of the action of the active substances of fungicides. The obtained data prove that the action of fungicides changes the synthesis of ethylene by soybean plants, as well as the processes of nodulation and nitrogen fixation, which depend on the efficiency of the formed soybean-rhizobial systems and their ability to realize their symbiotic potential under appropriate growing conditions.

Keywords: Bradyrhizobium japonicum; Glycine max; 1-aminocyclopropane-1-carboxylic acid; symbiotic system.

\section{Introduction}

The phytohormone ethylene has been known as a negative regulator of the nodulation process for almost four decades. Since then, significant progress has been made in understanding both the transduction of ethylene signaling pathways and the nodulation process. Its negative effect is manifested in the early stages of symbiosis development - before or during the release of calcium ions induced by the action of Nod factors. It has been proven (Oldroyd, 2011) that in Medicago truncatula it regulates the expression of early nodulation genes ENOD11, RIP1, and thus may affect the processes of calcium ion release. Ethylene treatment effectively inhibits Nod factor-induced calcium ion release and expression of early ENOD nodulation genes by disrupting Nod factor signaling pathways (Hayashi et al., 2010; Ju et al., 2012). Finding out exactly how ethylene signaling pathways regulate calcium release will provide a clear understanding of ethylene-mediated local inhibition of nodulation in its early stages (Kots \& Hryshchuk, 2019).

It is proved that two ethylene regulatory pathways are established for inoculation with rhizobia of legumes (Larrainzar et al., 2015). The first path is fast (1 hour), is temporary, independent of Nod factors and posi- tively controlled by ethylene. The second occurs more slowly (6 hours), depends on the perception of Nod factors and is negatively controlled by this phytohormone (Larrainzar et al., 2015). The first pathway is probably part of a defensive reaction, while the latter is responsible for activating nodulation programs and negatively affects several hormonal signaling pathways. This led the authors to propose a major negative regulatory role for ethylene. After inoculation of legume rhizobia, it was found that the key enzymes in the biosynthesis of ethylene with 1-aminocyclopropane-1carboxylic acid, aminocyclopropanecarbo-synthase and aminocyclopropanecarbo-oxidase are produced, as a result of which it forms in the nodulation zone (Larrainzar et al., 2015). These results are confirmed in the works of many authors who noted the induction of ethylene biosynthesis by Nod factors (Miyata et al., 2013; van Zeijl et al., 2015) and increasing its emission at early stages of legume-rhizobium symbiosis formation (Suganuma et al., 1995; Lopez-Gomez et al., 2012).

The negative effect of ethylene on the processes of nodulation and nitrogen fixation of root nodules was found in the study of pea plants (Pisum sativum L.), beans (Phaseolus vulgaris L.), clover (Trifolium repens L.) (Tamimi \& Timko, 2003; Ferguson et al., 2011; Khatabi \& Schäfer, 2012). Thus, treatment of the roots of alfalfa plants (Medicago 
sativa L.) with an inhibitor of ethylene synthesis by aminoethoxyvinylglycine led to an increase in the number of nodules formed, which testified to its participation in the regulation of nodulation in legumes (Prayitno et al., 2006; Prayitno, 2010). In addition, in inoculated pea plants (P. sativum L.), nodule primordia are laid opposite to the xylem poles, whereas the enzyme aminocyclopropanecarbo oxidase, which controls the final stage of phytohormone biosynthesis, is localized opposite the phloem poles (Prayitno, 2010). Treatment of pea roots with inhibitors of phytohormone synthesis by aminoethoxyvinylglycine or silver led to the formation of nodules opposite the phloem poles (Lee \& LaRue, 1992a, 1992b). This indicates its participation in the processes associated with determining the location of the nodules on the roots of plants. Ethylene controls the site of the initiation of nodules, their number and the growth of nodule primordia (Lohar et al., 2009). Ethylene blocks the development of nodules at different stages of development, and its action is manifested in blocking one or more of the early stages of nodule development independently (Oldroyd et al., 2001). Thus, it has been established that in inoculated plants of Sinorhizobum meliloti, there is an intensification of ethylene synthesis, which can participate in the regulation of successful infection and formation of root nodules by inhibiting further infection or blocking part of already developed infectious filaments (Oldroyd et al., 2001; Oldroyd, 2011). In addition, it blocks root hair deformity and the initiation of infectious filament growth in M. truncatula (Guerra et al., 2010; Guan et al., 2013).

In the last decade, a great deal has been found through the use of ethylene signaling pathway mutants and transgenic plants carrying ethylene-related genes. However, there is still far from a complete understanding of the effect of the hormone on the processes of nodulation. Particularly useful for such studies has been the supernodulating mutant M. truncatula Mtskl., which is hypersensitive to Nod factors (Penmetsa \& Cook, 1997; Oldroyd \& Downie, 2008; Prayitno \& Mathesius, 2010; Oldroyd, 2011). This makes it useful for research in the field of transcriptomics, since gene expression induced by Nod factors is more regulated in skl than in wild-type plants (Breakspear et al., 2014; Larrainzar et al., 2015). The Mtskl M. truncatula mutant is insensitive to ethylene because it does not exhibit the classic "triple response" by treatment with aminocyclopropanecarboxylic acid or ethylene (Penmetsa \& Cook, 1997). It has been proven that Mtskl is the AtEIN2 orthologist - an integral membrane protein comprising an $\mathrm{N}$-terminal sequence similar to proteins belonging to the macrophage protein family associated with natural resistance (NRAMP) (Penmetsa et al., 2008). Its hydrophobic nucleus consists of 10 transmembrane domains, which are located inside its N-terminal end. A study of transgenic plants confirmed the results obtained using Mtskl that ethylene suppresses nodulation. This is due to a mutation of the EIN2 gene (ethylene insensitive 2), a key component of the regulation of ethylene signaling. As a result, the supernodulatory mutant of $M$. truncatula becomes insensitive to the influence of this phytohormone and produces 10 times more nodules compared to wild-type plants (Penmetsa \& Cook, 1997). To date, one EIN2 gene was found in M. truncatula (Penmetsa et al., 2008), pea and chickpea (Weller et al., 2015), while two were found in common beans (Weller et al., 2015), in soybean (Miyata et al., 2013) and in L. japonicus (Chan et al., 2013). Moreover, two genes L. japonicus LjEIN2a and LjEIN2b are expressed in all studied organs, including roots and nodules (Miyata et al., 2013). The presence of two EIN2 genes in common beans, soybeans and L. japonicus, as well as in all plants that form determinate nodules, may partly explain the mystery of why soybean nodules are formed in the presence of ethylene (Lee \& LaRue, 1992a) and ethylene-insensitive mutants (Schmidt et al., 1999). These observations led to the hypothesis that the formation of indeterminate and determinate nodules may be regulated differently by this phytohormone.

It was proved that, in contrast to pea and alfalfa, in soybean, ethylene does not play a significant role in the regulation of nodulation, which is associated with various types of formed nodules - indeterminate in the first case and determinate in the second (Schmidt et al., 1999). This led to a detailed study of the role of this phytohormone in nodulation of soybean plants using mutant lines that were insensitive to its action, in particular, T119N54 with a mutation in the etr-1 gene encoding one of its receptors (Suganuma et al., 1995; Schmidt et al., 1999). In the treat- ment of aminoethoxyvinylglycine in plants of wild-type Hobbit 87, in contrast to the mutant etr-1, a decrease in the number of formed nodules on soybean roots was observed, which explained the influence of ethylene on the development of the root system of plants, reduction of root length. At the same time, no difference was observed in the wild-type Hobbit 87 and the ethylene-insensitive mutant etr1-1 in the number of nodules formed on soybean roots, both in treated and non-treated silver thiosulfate (ethylene inhibitor) plants. In addition, it was found that ethylene also did not participate in the negative regulation of nodulation by nitrate (Xia et al., 2017).

It is known that some legumes that form determinate nodules respond to ethylene. The sensitivity of the nodulation to phytohormone was shown for a bean plant with determinate nodules - pea ( $P$. sativum), in which treatment with aminoethoxyvinylglycine and cobalt ions increased the number of nodules on the roots, while ethephon reduced it (Nukui et al., 2000; Tamimi \& Timko, 2003). Differences in the response of ethylene are observed in L. japonicus transgenic plants insensitive to it, carrying the vector with mutated etr1-1 from Arabidopsis (Lohar et al., 2009). The various lines of Lotus japonicus were obtained and classified according to their hypocotyl responses to treatment with aminocyclopropanecarboxylic acid: the "hypersensitive" lines have a number of nodules similar to the number in wild-type plants, while the lines are "hypersensitive" with signs of the absence of ethylene responses and with a large number nodules (Lohar et al., 2009). Therefore, it has been suggested that the insensitivity of the nodulation in soybeans to ethylene is not related to the type of nodules formed, since in other legumes the development of the nodules is a process sensitive to the phytohormone (Xie et al., 1996; Nukui, 2000). This issue requires further careful study.

Scientists have determined that rhizobia can control the level of ethylene released, reducing its negative role in nodulation (Ma et al., 2002). Thus, Bradyrhizobium elkanii strains produce rhizobitoxin, an inhibitor of aminocyclopropanecarbo-synthase, which reduces the intensity of phytohormone secretion and increases the number of nodules on the roots of the host plant. Another mechanism for reducing ethylene release is the presence in the rhizobia of the enzyme aminocyclopropanecarbo-deaminase, which decomposes aminocyclopropanecarboxylic acid (Ma et al., 2003). Deaminase is thought to act not on the pool of aminocyclopropanecarboxylic acid present in the plant during inoculation, but on any molecules of this acid that are synthesized subsequently (Gamalero \& Glick, 2015). These two acid pools reflect different ethylene release peaks observed in rhizobia inoculation of plants (Ligero et al., 1986). Thus, aminocyclopropanecarbo-deaminase will reduce ethylene synthesized later rather than its early release peak, which is observed in the host immune response and therefore will not interfere with the plant's protective responses, but will at the same time promote the formation of a greater number of nodules. However, not all researchers agree with this useful role of rhizobial aminocyclopropanecarbo-deaminase, since its inhibition in different types of rhizobia leads to mixed results and nodulation depletion has not been observed in all species. In particular, when studying the interaction of Bradyrhizobium japonicum - soybean, it was questioned whether aminocyclopropanecarboxylic acid was a true substrate of aminocyclopropanecarbo-desaminase, since the bacterial protein used both this enzyme and d-serine, albeit less efficiently (Murset et al., 2012). The authors suggested another role for aminocyclopropanecarbo-deaminase, as they observed that its gene was overproduced under micro-oxygen conditions, that this enzyme acts in the regulation of metabolism in anoxic conditions and is important for nodules function, not for reducing ethylene in the plant (Murset et al., 2012).

Despite significant advances in the study of the role of ethylene in nodulation processes, the data obtained are still too limited to be used from a practical point of view. The rhizosphere is a complex environment, so the use of any chemical compounds that affect the ethylene evolution can have different effects on both rhizobia and other microorganisms. In addition, there are quite conflicting opinions in the literature regarding the involvement of phytohormone in the regulation of ethylene synthesis in plants with determinate meristem type, in particular soybean, as a sufficiently sensitive and specific culture to the influence 
of external factors. In this regard, our aim was to study the effect of presowing treatment of soybean seeds with fungicides on the intensity of ethylene release in plants at early stages of the legume-rhizobial symbiosis formation.

\section{Materials and methods}

The objects of the study are chosen symbiotic systems, formed with participation of soybean (Glycine max (L.) Merr.) Diamond variety, strains of various effectiveness of Bradyrhizobium japonicum 634b (active, virulent) and $604 \mathrm{k}$ (inactive, highly virulent) and fungicidal Maxim XL 035 PS (fluvidoxonil, $25 \mathrm{~g} / \mathrm{L}$, metalaxyl, $10 \mathrm{~g} / \mathrm{L}$ ) and Standak Top (fipronil, $250 \mathrm{~g} / \mathrm{L}$, thiophanate methyl, $225 \mathrm{~g} / \mathrm{L}$, piraclostrobin, $25 \mathrm{~g} / \mathrm{L}$ ). We used B. japonicum strains from the museum collection of the symbiotic nitrogen fixation department of the Institute of Plant Physiology and Genetics of the National Academy of Sciences of Ukraine. Before sowing, soybeans were treated with solutions of fungicides, calculated on the basis of one rate of expenditure of the active substance of each preparation indicated by the producer per ton of seeds.

For research, fungicides were used that differed in the spectrum of action of active substances. In particular, the active ingredients (fipronil, thiophanate-methyl, pyraclostrobin), which are part of Standak Top, combine fungicidal and insecticidal action. Each of these substances has a special mechanism of action, as well as the duration of protective action. In particular, the action of fipronil consists in blocking gammaaminobutyric acid, which regulates the passage of the nerve impulse through chlorine channels in the membranes of the nerve cells, causing a violation of the function of the nervous system of insects. Piraclosterobine interferes with mitochondrial breathing, blocking the transport of electrons, and violates the energy exchange in a fungus cell. Thiophanate-methyl suppresses the formation of ergosterol, as well as the biosynthesis of nucleic acids in fungal cells (www.demetra-agra.com.ua). The fungicide Maxim XL contains two active ingredients (fludioxonil and metalaxyl), one of which, fludioxonil, is an analogue of a natural antibiotic and is excreted by soil bacteria Pseudomonas pyrocinia, which inhibit the growth of pathogenic fungi. Influence of substances of the subclass of triazolintion on the growth and reproduction of the pathogen is associated with a violation of the function of cell membranes (www.demetra-agra.com.ua).

One part of the seeds treated with fungicides was inoculated with suspension of rhizobium culture 1 hour. The culture of rhizobium was grown on solid mannitol - yeast medium for 9 days at $26-28^{\circ} \mathrm{C}$ (the titer of bacteria was $10^{7}$ cells $/ \mathrm{mL}$ ). The other part of fungicide-treated seeds was not inoculated by rhizobium culture.

Plants were grown in sand pots in the application of a nutritional mixture of Gelrigel with 0.25 nitrogen rates from natural light and optimal water supply. For research, soybean roots were selected in the early stages of ontogenesis - seedlings leaves, primordial leaves, first true leaf, second true leaf, and root nodules in the stage of third true leaf. The control options were: non-inoculated plants without fungicide treatment, and inoculated with strains $634 \mathrm{~b}$ and $604 \mathrm{k}$ without using fungicide treatment.

The nodulation ability of B. japonicum was determined by counting the number and mass of root nodules. Nitrogen fixation activity (NFA) (acetylene reduction activity) of intact plants was measured on gas chromatograph "Agilent GC system 6850" (USA) with flame-ionization detector (Hardy et al., 1968). The separation of gases was carried out on a column (Supelco Porapak N) at a thermostat temperature of $55^{\circ} \mathrm{C}$ and a detector $-150{ }^{\circ} \mathrm{C}$. The carrier gas was helium $(20 \mathrm{~mL}$ per 1 minute). The volume of the analyzed sample of the gas mixture was $1 \mathrm{~cm}^{3}$. As a standard, pure ethylene (Sigma-Aldrich, USA) was used. The amount of ethylene formed from acetylene in 1 hour by the action of nitrogenase, that is, the total nitrogen fixation activity was expressed in molar units of ethylene formed per 1 hour $\left(\mu \mathrm{mol} \mathrm{C}_{2} \mathrm{H}_{4} /\right.$ plant $\left.\bullet h\right)$. The specific nitrogen fixation activity was calculated on the mass of root nodules from one plant and expressed in molar units of ethylene formed in 1 hour $\left(\mu \mathrm{mol} \mathrm{C}_{2} \mathrm{H}_{4} / \mathrm{g}\right.$ nodules $\left.\bullet \mathrm{h}\right)$.

To determine the intensity of ethylene evolution the plant samples were placed in $75 \mathrm{~mL}$ glass vials, which were sealed immediately and left in the dark for 24 h (Guzmán \& Ecker, 1990). After incubation, the gas mixture containing ethylene was analyzed on gas chromatograph "Agilent GC system 6850" (USA). The volume of the analyzed sample gas mixture was $1 \mathrm{~cm}^{3}$. As a standard, pure ethylene (Sigma-Aldrich, USA) was used. The amount of ethylene evolution from the incubated sample was expressed in nmoles at the rate of one plant per hour (nmol $\mathrm{C}_{2} \mathrm{H}_{4}$ plant $\bullet \mathrm{h}$ ).

The results were statistically analyzed in the Statistica 6.0 (Statsoft Inc., USA) program pack. The tables and figures show the arithmetic mean values and their standard errors $(x \pm S E)$. The reliability of the differences between the samples was evaluated using the single-factor dispersion analysis (ANOVA), using the Mann-Whitney U-criterion. Differences were considered to be significant at $\mathrm{P}<0.05$.

\section{Results}

The pre-sowing treatment of soybean seeds with fungicides without inoculation with rhizobia did not lead to significant changes in the intensity of ethylene release by plants into the the seedlings leaves stage (Fig. 1). In the following stages of ontogenesis - primordial leaves, the first and second true leaves - there was an increase in the release of phytohormone by soybean plants. In particular, with the action of the fungicide Maxim its production increased by $41.7 \%$ in the primordial leaves stage and by $30.5 \%$ in the first true leaves stage. With pre-sowing seed treatment with fungicide Standak Top, ethylene synthesis by soybean plants increased by $52.8 \%$ in the primordial leaves stage, but its largest production is recorded in the first true leaf stage by $99.8 \%$ of the level of nontreatment plants. It was found that in the stage of the second true leaf the intensity of phytohormone release by plants exceeded the level of unprocessed plants by $18.1 \%$ for Maxim and $44.9 \%$ for Standak Top.

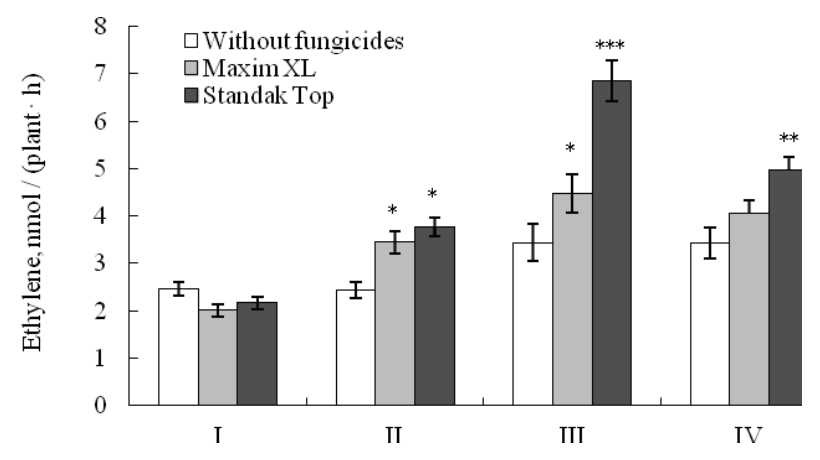

Fig. 1. Influence of fungicides on the intensity of ethylene $\left(\mathrm{C}_{2} \mathrm{H}_{4}\right)$ release by non-inoculated soybean plants in the early stages of ontogenesis: I - seedlings leaves, II - primordial leaves, III - first true leaf, IV - second true leaf $(x \pm S E, n=8)$; data compared to control (without fungicides) are reliable at $*-\mathrm{P}<0.05,{ }^{* *}-\mathrm{P}<0.01,{ }^{* * *}-\mathrm{P}<0.001$; here and in Fig. 2 and 3 the reliability of the differences between the samples was evaluated using the single-factor dispersion analysis (ANOVA), using the Mann-Whitney U-criterion

The pre-sowing treatment of soybean seeds with fungicides together with inoculation with the rhizobia of the inactive strain $604 \mathrm{k}$ did not induce significant changes in the intensity of ethylene release by plants into the seedlings leaves stage (Fig. 2). This is evidenced by the lack of a reliable difference between the variants of the experiment with the treatment of fungicides against inoculation with rhizobia and without their use. Significant changes between the variants of the experiment were recorded in the primordial leaves stage, which were manifested in the reduction of phytohormone synthesis by plants by $30.5 \%$ for Maxim and by $19.9 \%$ for Standak Top, compared with plants not treated with fungicides. In the stages of the first and second true leaves, no significant changes in the intensity of phytohormone release due to fungicides in this symbiotic system were detected.

The use of pre-sowing treatment of soybean seeds with fungicide Standak Top together with inoculation by active strain of B. japonicum $634 \mathrm{~b}$ no significant changes were found in the release of phytohormone by plants into the seedlings leaves stage. At the same time, the action of 
Maxim fungicide was accompanied by a decrease of phytohormone synthesis by $29.1 \%$ (Fig. 2). An increase in the level of phytohormone release in this symbiotic system involving fungicides was observed in the primordial leaf stage. In particular, the intensity of ethylene production by plants increased by $24.2 \%$ with the action of Maxim fungicide and by $26.6 \%$ with the action of Standak Top. The highest level of ethylene release was observed in the stage of the first true leaf in all variants of the experiment using pre-sowing seed treatment with fungicides and inoculation with the active strain of B. japonicum 634b.

Despite the fact that with the action of fungicides its production was slightly reduced in this symbiotic system, the results are still within the margin of error of the experiment. In the stage of the second true leaf with the participation of fungicides Maxim and Standak Top together with inoculation of rhizobia of the active strain, phytohormone secretion by soybean plants was reduced by $28.4 \%$ and $19.4 \%$ respectively.

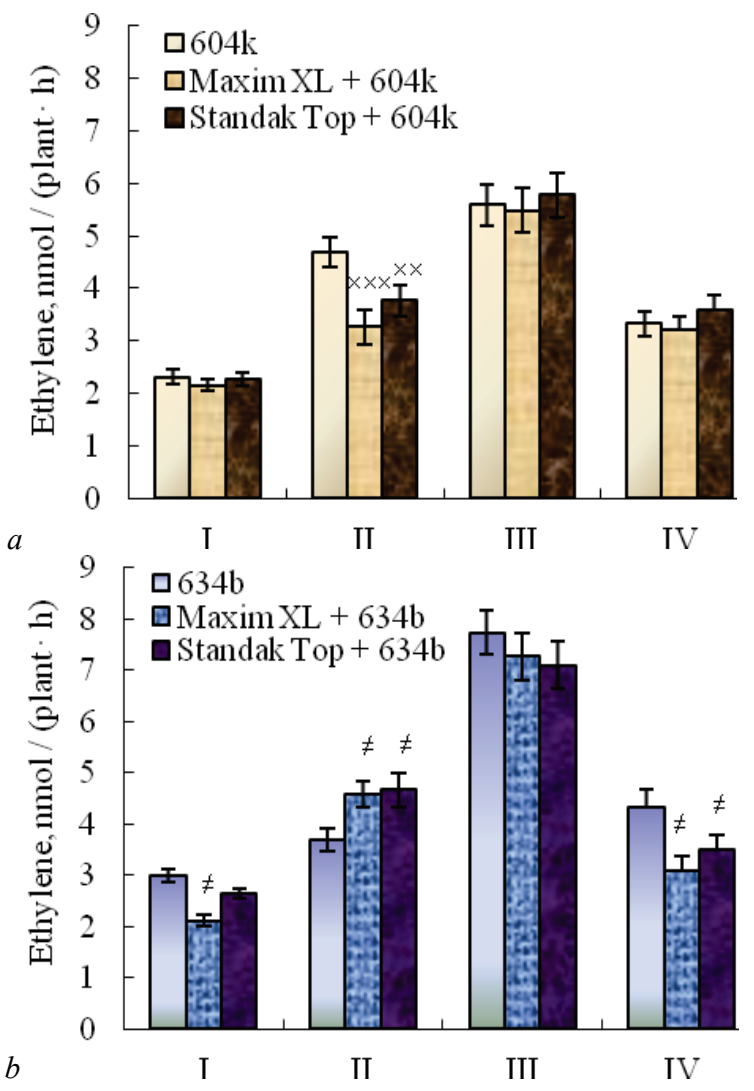

Fig. 2. Influence of fungicides on the intensity of ethylene release by soybean plants during inoculation of seeds with with inactive strain $604 \mathrm{k}$ (A) and active strain $634 \mathrm{~b}$ (B) of B. japonicum in the early stages of ontogenesis: I - seedlings leaves, II - primordial leaves - first true leaf, IV - second true leaf $(\mathrm{x} \pm \mathrm{SE}, \mathrm{n}=8)$; data compared with control are reliable at ${ }^{\neq \times}-\mathrm{P}<0.05,{ }^{\# \times x}-\mathrm{P}<0.01\left(^{\neq}\right.$and $^{\times}$- relative to variants with inoculation of strains $634 \mathrm{~b}$ and $604 \mathrm{k}$, respectively); see Fig. 1

With the use of fungicidal preparations in an ineffective symbiotic system formed with the participation of an inactive highly virulent rhizobium $604 \mathrm{k}$ strain, we observed a decrease in the number and weight of nodules on the plant roots in the stage of the second true leaf. In particular, for the actions of Maxim fungicide by $26.3 \%$ and for the actions of Standak Top by $22.1 \%$ (Table 1 ). In an effective symbiotic system formed with the participation of the active virulent strain $634 \mathrm{~b}$, the use of pre-sowing treatment of soybean seeds with fungicides led to an increase in the number of nodules on the roots and a decrease in their weight in the stage of the second true leaf. In particular, the action of Maxim fungicide increased the number of root nodules by $12.7 \%$, and under the action of Standak Top by $40.1 \%$, whereas the weight of nodules decreased by 18.8 and $31.8 \%$, respectively.
It was determined that the reduction of the weight of nodules on the roots of plants in the stage of the second true leaf did not significantly affect the indices of specific and total nitrogen fixing activity (Fig. 3).

Table 1

Influence of fungicides on the formation of symbiotic apparatus in soybean nodules by inoculated with $B$. japonicum $(\mathrm{x} \pm \mathrm{SE}, \mathrm{n}=8)$

\begin{tabular}{|c|c|c|c|c|}
\hline \multirow[b]{2}{*}{ Fungicides } & \multicolumn{2}{|c|}{ Stage of first true leaf } & \multicolumn{2}{|c|}{ Stage of second true leaf } \\
\hline & $\begin{array}{c}\text { number, } \\
\text { pieces / plant }\end{array}$ & $\begin{array}{c}\text { weight, } \\
\mathrm{mg} / \text { plant }\end{array}$ & $\begin{array}{c}\text { number, } \\
\text { pieces / plant }\end{array}$ & $\begin{array}{l}\text { weight, } \\
\mathrm{mg} / \text { plant }\end{array}$ \\
\hline Strain 634b & $11.12 \pm 0.78$ & $22 \pm 1.5$ & $16.51 \pm 1.12$ & $69 \pm 2.8$ \\
\hline $\begin{array}{l}\text { Maxim XL+ } \\
\text { strain 634b }\end{array}$ & $11.92 \pm 0.72$ & $18 \pm 1.1^{\neq}$ & $18.62 \pm 1.32^{\neq}$ & $56 \pm 2.2^{\neq}$ \\
\hline $\begin{array}{l}\text { Standak Top + } \\
\text { strain } 634 \mathrm{~b}\end{array}$ & $12.81 \pm 0.84$ & $18 \pm 1.4^{\neq}$ & $23.14 \pm 1.64^{\#}$ & $47 \pm 2.1^{\#}$ \\
\hline Strain $604 \kappa$ & $17.88 \pm 1.21$ & $31 \pm 1.8$ & $33.41 \pm 2.36$ & $61 \pm 2.3$ \\
\hline $\begin{array}{l}\text { Maxim XL+ } \\
\text { strain 604k }\end{array}$ & $18.72 \pm 1.34$ & $33 \pm 1.8$ & $24.62 \pm 1.52^{\times}$ & $37 \pm 1.6^{x x}$ \\
\hline Standak Top + & $17.35 \pm 1.27$ & $23 \pm 1.4^{x \times}$ & $26.11 \pm 1.71^{\times}$ & $55 \pm 1.8^{\times}$ \\
\hline
\end{tabular}

strain $604 \mathrm{k}$

Note: ${ }^{\neq \times}-$data compared to the control are reliable at ${ }^{\neq \times}-\mathrm{P}<0.05 ;{ }^{\# \times x}-\mathrm{P}<$ $0.01\left(^{\ddagger}\right.$ and $^{\times}$- relative to the variants with inoculation with strains $634 \mathrm{~b}$ and $604 \mathrm{k}$, respectively); the reliability of the differences between the samples was evaluated using the single-factor dispersion analysis (ANOVA), using the Mann-Whitney U-criterion; here and in Fig. 3 presents the average values for two years.
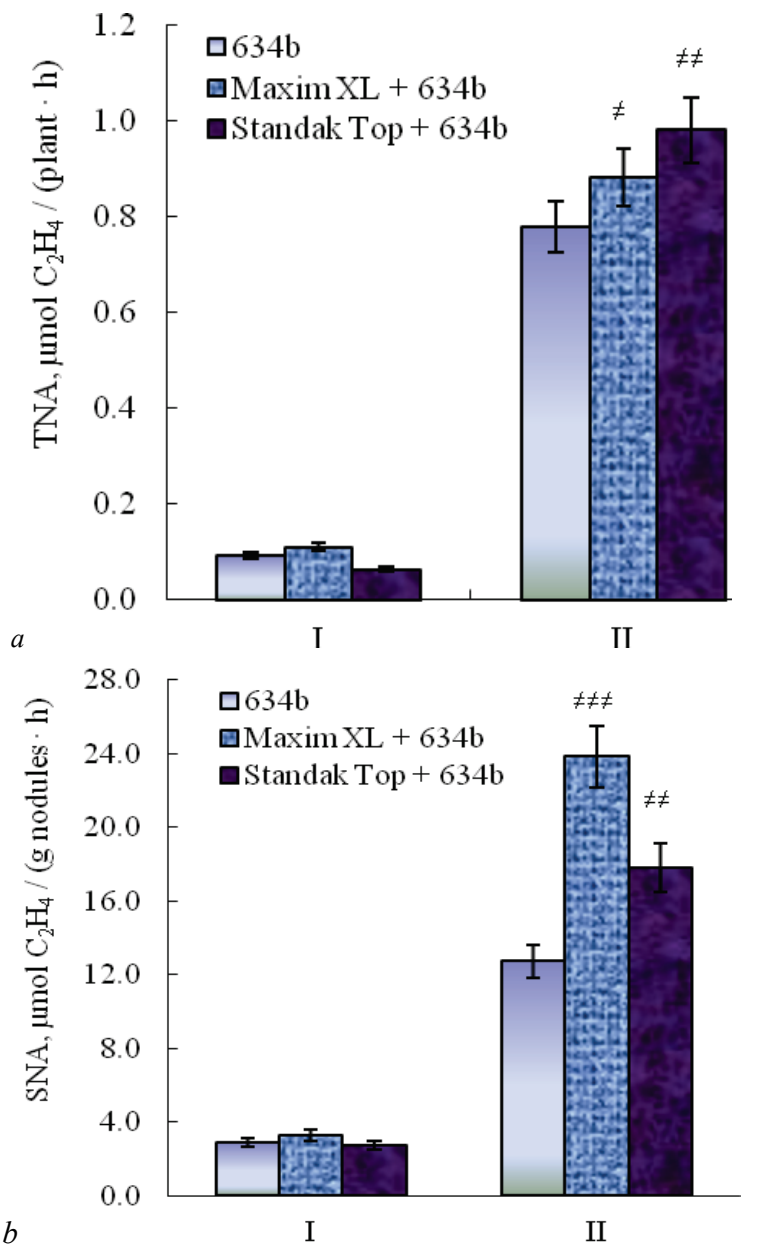

Fig. 3. Influence of fungicides on the total (TNA) and specific (SNA) nitrogenase activity of soybean plants after inoculation of seeds with active strain $634 \mathrm{~b}$ of B. japonicum in the early stages of ontogenesis: I - seedlings leaves, II - primordial leaves - first true leaf, IV - second true leaf $(\mathrm{x} \pm \mathrm{SE}, \mathrm{n}=8)$; data compared with control (634b) are reliable at $^{\ddagger}-\mathrm{P}<0.05 ; \#-\mathrm{P}<0.01 ; \#-\mathrm{P}<0.001$; see Fig. 1

In particular, we observed an increase in these soybean indices by coinoculation with the rhizobia of the active strain $634 \mathrm{~b}$ and fungicides in the stage of the second true leaf compared to the variant without using them. Thus, in the stage of the second true leaf the total nitrogen fixing activity of 
root nodules increased by 13.5 under the influence of Maxim and by $26.1 \%$ under the influence of Standak Top, while the specific nitrogen fixing activity increased by 87.1 and $39.8 \%$ respectively.

\section{Discussion}

For several decades, ethylene was considered as a phytohormone which adversely affects the regulation of nodules' formation both at the earliest (during calcium oscillations caused by the Nod factor) and subsequent (growth of the infectious filament, laying of nodule primordia and maintaining nodule meristems) stages their development (Tsyganova \& Tsyganov, 2015). It has been shown that in the formation of legume-rhizobial symbiosis, it is involved in the immune response of the host plant, the organogenesis of the nodules, the location of the nodules on the roots, bacterial differentiation and aging of the nodules (Gourion et al., 2015). It has now been found that this phytohormone plays a positive role in legume-rhizobial symbiosis as it regulates transcription processes at certain stages (Larrainzar et al., 2015).

Ethylene plays a leading role in determining the type of nodules determinate (with limited activity of the meristem) or indeterminate (with long-term activity of the meristem), since its negative effect on the functioning of nodule meristems was found (Gourion et al., 2015). Studies using ethylene inhibitors showed that the addition of silver to the substrate of plant growth leads to the formation of indeterminate nodules and the ethephon (2-chloroethylphosphonic acid, decomposes with the release of ethylene) - determinate (Suganuma et al., 1995). In soybean plants, which form nodules with a determinate type of meristem, an inhibitor of the action of the phytohormone ethephone does not induce inhibition of nodulation processes, compared with legumes, which form indeterminate nodules (Schmidt et al., 1999).

We have shown that, regardless of the effectiveness of soybean rhizobial symbiosis, the highest level of ethylene release by plants occurs in the primordial leaf stages and the first true leaf, which is obviously due to the initial processes of nodulation - the laying of nodule primordia and the active formation of nodules on the roots of soybeans. It was established that in the stage of the second true leaf the intensity of phytohormone release by plants decreases in both symbiotic systems. In our opinion, this is due to the activation of the processes of nodulation on the roots of plants, which are confirmed by the presented studies on the increase in the number and weight of nodules on the roots of soybeans in the stage of the second true leaf, compared with the previous stage of ontogenesis of the first true leaf. A similar tendency of nodulation processes in the early stages of soybean ontogenesis has been identified in previous studies (Mamenko et al., 2019).

The data obtained by us are in accordance with those known in the literature, which indicates that four weeks after inoculation of soybean by rhizobia activation of ethylene release and accumulation of its synthesis precursor, aminocyclopropanecanoic acid is observed in plants (Gourion et al., 2015). The amount of ethylene produced by plants was independent of the effectiveness of the rhizobia strain. Studies using aminoetoxivinylglycine, an inhibitor of the phytohormone synthesis, have shown a decrease in the intensity of its evolution, which did not affect the number of root nodules of inoculated soybeans (Suganuma et al., 1995; Schmidt et al., 1999).

Legume-rhizobial interaction is initiated by the release of plant exudates, such as flavonoids, due to which chemotaxis of rhizobia to the root occurs. By binding to the rhizobial NodD1 protein, flavonoids contribute to the initiation of Nod factor biosynthesis, which are recognized by the LysM receptor kinases NFR1 and NFR5 (Nod-Factor Receptor) (Peck et al., 2006; Desbrosses \& Stougaard, 2011). This leads to the activation of a common signal transduction pathway (CCaMK signaling), which is involved in the initiation of rhizobial and arbuscular mycorrhizal symbioses (Kistner et al., 2005).

Recent studies have shown that there is a fine balance in the interaction between bacteria with their microbial-associated molecular patterns (MAMPs) and a plant with its induction of MAMP-triggered immunity MTI (FLagellin-Sensing) (Gourion et al., 2015). Rhizobia produce not only Nod factors but also flagellin-like molecules (flg22) that are recognized by FLS2 (FLagellin-Sensing) receptors located in the plasmolemma of the epidermis (Khatabi \& Schäfer, 2012). In response to these molecules, the host plant cell induces a cascade of effects such as the release of calcium ions and the production of reactive oxygen species. In addition, many genes, such as coding peroxidases, chitinases, or ERFs (ethylene relevant factors) are regulated. This temporary protective response depends on the Nod factor LjNFR1 receptor (Nakagawa et al., 2011).

It is now accepted that active ethylene synthesis in the roots of legumes is initiated as a result of the action of Nod factors produced by rhizobia (Tsyganova \& Tsyganov, 2015). At the same time, studies conducted in recent years have shown the adverse effect of drugs with fungicidal activity on the effectiveness of legume-rhizobial symbiosis. This is manifested in the violation of the regulatory signaling system between macro- and microsymbionts, blocking the activity of nodulation genes and reducing the level of the rhizobial Nod factor (Bikrol et al., 2005; Nason et al., 2007). Fungicidal drugs affect the inhibition of flavanoid Nod receptor, which induces inhibition of the synthesis and secretion of flavonoid substances produced by the plant. Thus, they violate legume-rhizobial signaling (Bikrol et al., 2005; Fox et al., 2007; Standish et al., 2018).

We have shown that the pre-sowing treatment of soybean seeds with fungicides together with inoculation with an inactive rhizobium $604 \mathrm{k}$ strain leads to a decrease in the intensity of ethylene release into the primordial leaves stage. No characteristic features of the synthesis of phytohormone by soybean plants with the participation of fungicides in the stages of the first and second true leaves were revealed, compared with the variants without their use in this symbiotic system. However, there were differences in the processes of nodulation on the roots of plants in the stage of the second true leaf with the co-treatment of seeds with fungicides and rhizobia of the inactive highly virulent strain $604 \mathrm{k}$, compared with previous studies (Mamenko et al., 2019). In particular, in the ineffective symbiotic system, due to the action of fungicides, the suppression of the nodulation processes into the stage of the second true leaf was recorded, which was manifested in the reduction of the number and weight of the formed nodules at the roots of the plants.

It should be noted that soybeans are a very sensitive crop in terms of growing conditions, so any changes in environmental conditions, especially temperature and humidity, can affect the formation of its symbiotic apparatus. In our opinion, the change in air temperature could have been a crucial factor in influencing the processes of nodulation and nitrogen fixation during research. This is especially true of an inefficient soybean rhizobial system that is not capable of realizing its symbiotic potential, on the one hand, and adapting to growing conditions, on the other. In the presented studies, an additional factor influencing the formation of microbial-plant relationships is the action of fungicides as a stress factor, which also affects the ability of the formed symbiotic systems to realize their adaptive potential. This indicates the feasibility of further research in this direction.

It is believed that the formation of "stress" ethylene is one of the fastest reactions to external influences (Urao et al., 2002; Wang et al., 2002). Its release is realized only in the presence of oxygen and indicates the transition of cellular metabolism to a stress state (Wang et al., 2002). We have found that the action of fungicides in non-inoculated soybeans intensifies the release of ethylene by plants during the early stages of ontogenesis - primordial leaves, the first and second true leaves, especially in the Standak Top treatment. This supports our view that pre-sowing soybean seeds with fungicides for plants is an additional stress factor affecting its metabolism. In the presented studies, this is manifested in the increased production of "stress" phytohormone of ethylene by plants of non-inoculated soybeans, the seeds of which were pre-treated with fungicides.

When forming an effective symbiotic system, formed with the participation of soybeans and the active strain of rhizobia $634 \mathrm{~b}$, the pre-sowing treatment of seeds with fungicides induces an increase of ethylene release into the primordial leaves stage. The stage of the first true leaf also recorded an increase in the production of ethylene by plants in this symbiotic system, which did not depend on the nature of the action of the active substances of fungicides, because no significant difference was found between the variants of the experiment. In the stage of the second true leaf, the intensity of phytohormone release by soybean 
plants is reduced by co-treatment with fungicides and the active rhizobia strain $634 \mathrm{~b}$. It is noted that in the effective symbiotic system with the participation of fungicides there was an increase in the number of root nodules, but there was a decrease in their weight in the stage of the second true leaf. It should be noted that this did not affect negatively the indicators of total and specific nitrogen fixation activity as their values increased. We have observed a similar tendency to increase nitrogen fixation in this symbiotic system due to fungicides in previous studies (Mamenko et al., 2019). However, the intensity of total nitrogen fixation activity was lower than in previous studies, and the specific nitrogen fixation activity on the contrary increased, especially with the action of Maxim fungicide.

\section{Conclusions}

Regardless of the effectiveness of soybean rhizobial symbiosis, the highest levels of ethylene release by plants are observed in the primordial leaves' stage and the first true leaf, which is associated with the initial processes of nodulation - the laying of nodules primordia and the active formation of nodules on soybean roots.

Pre-sowing treatment of soybean seeds with fungicides together with inoculation with an inactive rhizobia $604 \mathrm{k}$ strain leads to a decrease in ethylene synthesis by plants in the primordial leaves' stage and inhibition of nodulation processes into the second true leaf stage.

The use of soybean seed fungicides with the participation of the active rhizobium strain $634 \mathrm{~b}$ induces an intensification of ethylene release by plants into the primordial leaves' stage, which is accompanied by an increase in the number of root nodules, as well as their total and specific nitrogen-fixing activity.

\section{References}

Bikrol, A., Saxena, N., \& Singh, K. (2005). Response of Glycine max in relation to nitrogen fixation as influenced by fungicide seed treatment. African Journal of Biotechnology, 4(7), 667-671.

Breakspear, A., Liu, C., Roy, S., Stacey, N., Rogers, C., Trick, M., Morieri, G., Mysore, K. S., Wen, J., Oldroyd, G. E. D., Downie, J. A., \& Murray, J. D. (2014). The root hair "infectome" of Medicago truncatula uncovers changes in cell cycle genes and reveals a requirement for auxin signaling in rhizobial infection. Plant Cell, 26(12), 4680-4701.

Chan, P. K., Biswas, B., \& Gresshoff, P. M. (2013). Classical ethylene insensitive mutants of the Arabidopsis EIN2 orthologue lack the expected "hypernodulation" response in Lotus japonicus. Juornal of Integrative Plant Biology, 55(4), 395-408.

Tsyganova, A. V., \& Tsyganov, V. E. (2015). Negativnaya gormonal'naya regulyaczyiya razvitiya simbioticheskikh klben'kov. Soobshhenie I. Etilen. Negative hormonal regulation of symbiotic nodule development. I. Ethylene Sel'skokhozyajstvennaya Biologiya, 50(3), 267-277 (in Russian).

Desbrosses, G. J., \& Stougaard, J. (2011). Root nodulation: A paradigm for how plant-microbe symbiosis influences host developmental pathways. Cell Host and Microbe, 10(4), 348-358.

Ferguson, B. J., Foo, E., Ross, J. J., \& Reid, J. B. (2011). Relationship between gibberellin, ethylene and nodulation in Pisum sativum. New Phytology, 189(3), 829-842.

Fox, J. E., Gulledge, J., Engelhaupt, E., Burow, M. E., \& McLachlan, J. A. (2007). Pecticides reduce symbiotic efficiency of nitrogen-fixing rhizobia and host plants. Proceeding of the National Academy of Sciences USA, 104(24), 10282-10287.

Gamalero, E., \& Glick, B. R. (2015). Bacterial modulation of plant ethylene levels. Plant Physiology, 169(1), 1-10.

Guan, D., Stacey, N., Liu, C., Wen, J., Mysore, K. S., Torres-Jerez, I., Vernié, T., Tadege, M., Zhou, C., Wang, Z., Udvardi, M. K., Oldroyd, G. E. D., \& Murray, J. D. (2013). Rhizobial infection is associated with the development of peripheral vasculature in nodules of Medicago truncatula. Plant Physiology, 162(1), 107-115.

Guerra, J. C. P., Coussens, G., De Keyser, A., De Rycke, R., De Bodt, S., Van de Velde, W., Goormachtig, S., \& Holsters, M. (2010). Comparison of developmental and stress-induced nodule senescence in Medicago truncatula. Plant Physiology, 152(3), 1574-1584.

Guzmán, P., \& Ecker, J. R. (1990). Exploiting the triple response of Arabidopsis to identify ethylene-related mutants. Plant Cell, 2(6), 513-523.

Hardy, R. W. F., Holsten, R. D., Jackson, E. K., \& Burns, R. C. (1968). The acetylene-ethylene assay for nitrogen fixation: Laboratory and field evalution. Plant Physiology, 43(8), 1185-1207.
Hayashi, T., Banba, M., Shimoda, Y., Kouchi, H., Hayashi, M., \& Imaizumi-Anraku, H. (2010). A dominant function of CCaMK in intracellular accommodation of bacterial and fungal endosymbionts. Plant Journal, 63(1), 141-154.

Ju, C., Yoon, G. M., Shemansky, J. M., Lin, D. Y., Ying, Z. I., Chang, J., Garrett, W. M., Kessenbrock, M., Groth, G., Tucker, M. L., Cooper, B., Kieber, J. J., \& Chang, C. (2012). CTR1 phosphorylates the central regulator EIN2 to control ethylene hormone signaling from the ER membrane to the nucleus in Arabidopsis. Proceding of the National Academy of Sciences, 109(47), 19486-19491.

Khatabi, B., \& Schäfer, P. (2012). Ethylene in mutualistic symbioses. Plant Signaling and Behavior, 7(12), 1634-1638.

Kistner, C., Winzer, T., Pitzschke, A., Mulder, L., Sato, S., Kaneko, K., Tabata, S., Sandal, N., Stougaard, J., Webb, K. J., Szczyglowski, K., \& Parniske, M. (2005). Seven Lotus japonicus genes required for transcriptional reprogramming of the root during fungal and bacterial symbiosis. Plant Cell, 17(8), 2217-2229.

Kots, S. Y., \& Hryshchuk, O. O. (2019). Fitohormonalna rehuliatsiia bobovo-ryzobialnoho symbiozu [Phytohormonal regulation of legume-rhizobial symbiosis]. Fiziologiya Rastenij i Genetika, 51(1), 3-27 (in Ukrainian).

Larrainzar, E., Riely, B. K., Kim, S. C., Carrasquilla-Garcia, N., Yu, H.-J., Hwang, H.-J., Oh, M., Kim, G. B., Surendrarao, A. K., Chasman, D., Siahpirani, A. F., Penmetsa, R. V., Lee, G.-S., Kim, N., Roy, S., Mun, J.-H., \& Cook, D. R. (2015). Deep sequencing of the Medicago truncatula root transcriptome reveals a massive and early interaction between nod factor and ethylene signals. Plant Physiology, 169(1), 233-265.

Lee, K. H., \& LaRue, T. A. (1992a). Exogenous ethylene inhibits nodulation of Pisum sativum L. cv. Sparkle. Plant Physioljgy, 100(3), 1759-1763.

Lee, K. H., \& LaRue, T. A. (1992b). Pleiotropic effects of sym17. A mutation in Pisum sativum L. cv. Sparkle causes decreased nodulation, altered root and shoot growth, and increased ethylene production. Plant Physiology, 100(4), 1326-1333.

Ligero, F., Lluch, C., \& Olivares, J. (1986). Evolution of ethylene from roots of Medicago sativa plants inoculated with Rhizobium meliloti. Journal of Plant Physiology, 125(3-4), 361-365.

Lohar, D., Stiller, J., Kam, J., Stacey, G., \& Gresshoff, P. M. (2009). Ethylene insensitivity conferred by a mutated Arabidopsis ethylene receptor gene alters nodulation in transgenic Lotus japonicus. Annals of Botany, 104(2), $277-285$.

Lopez-Gomez, M., Sandal, N., Stougaard, J., \& Boller, T. (2012). Interplay of flg22-induced defence responses and nodulation in Lotus japonicus. Journal of Experimental Botany, 63(1), 393-401.

Ma, W., Guinel, F. C., \& Glick, B. R. (2003). Rhizobium leguminosarum biovar viciae 1-aminocyclopropane-carboxylate deaminase promotes nodulation of pea plants. Applied and Environmental Microbiology, 69(8), 4396-4402.

Ma, W., Penrose, D. M., \& Glick, B. R. (2002). Strategies used by rhizobia to lower plant ethylene levels and increase nodulation. Canadian Journal of Microbiology, 48(11), 947-954.

Mamenko, T. P., Khomenko, Y. O., \& Kots, S. Y. (2019). Influence of fungicides on activities of enzymes of phenolic metabolism in the early stages of formation and functioning of soybean symbiotic apparatus. Regulatory Mechanisms in Biosystems, 10(1), 111-116 (in Ukrainian).

Miyata, K., Kawaguchi, M., \& Nakagawa, T. (2013). Two distinct EIN2 genes cooperatively regulate ethylene signaling in Lotus japonicus. Plant Cell Physiology, 54(9), 1469-1477.

Murset, V., Hennecke, H., \& Pessi, G. (2012). Disparate role of rhizobial ACC deaminase in root-nodule symbioses. Symbiosis, 57(1), 43-50.

Nakagawa, T., Kaku, H., Shimoda, Y., Sugiyama, A., Shimamura, M., Takahashi, K. (2011). From defense to symbiosis: Limited alterations in the kinase domain of LysM receptor-like kinases are crucial for evolution of legumeRhizobium symbiosis. Plant Journal, 65(2), 169-180.

Nason, M. A., Farrar, J., \& Bartlett, D. (2007). Strobilurin fungicides induce changes in photosynthetic gas exchange that do not improve water use efficiency of plants grown under conditions of water stress. Pest Management Science, 63(12), 1191-1200.

Nukui, N., Ezura, H., Yuhashi, K.-I., Yasuta, T., \& Minamisawa, K. (2000). Effects of ethylene precursor and inhibitors for ethylene biosynthesis and perception on nodulation in Lotus japonicus and Macroptilium atropurpureum. Plant Cell Physiology, 41(7), 893-897.

Oldroyd, G. E. D., \& Downie J. A. (2008). Coordinating nodule morphogenesis with rhizobial infection in legumes. Annual Review of Plant Biology, 59(1), $519-546$.

Oldroyd, G. E. D., Engstrom, E. M., \& Long, S. R. (2001). Ethylene inhibits the Nod factor signal transduction pathway of Medicago truncatula. Plant Cell, 13(8), 1835-1849.

Oldroyd, G. E. D., Murray, J. D., Poole, P. S., \& Downie, J. A. (2011). The rules of engagement in the legume-rhizobial symbiosis. Annual Review of Genetics, 45(1), 119-144.

Peck, M. C., Fisher, R. F., \& Long, S. R. (2006). Diverse flavonoids stimulate NodD1 binding to nod gene promoters in Sinorhizobium meliloti. Journal of Bacteriology, 188(15), 5417-5427. 
Penmetsa, V. P., Uribe, P., Anderson, J., Lichtenzveig, J., Gish, J.-C., Nam, Y. W., Engstrom, E., Xu, K., Sckisel, G., Pereira, M., Baek, J. M., Lopez-Meyer, M., Long, S. R., Harrison, M. J., Singh, K. B., Kiss, G. B., \& Cook, D. R. (2008) The Medicago truncatula ortholog of Arabidopsis EIN2, sickle, is a negative regulator of symbiotic and pathogenic microbial associations. Plant Journal, 55(40), 580-595.

Prayitno, J. (2010). Root and nodulation phenotypes of the ethylene-insensitive sickle mutant of Medicago truncatula. Hayati Journal of Biosciences, 17(3), 131-136.

Prayitno, J., \& Mathesius, U. (2010). Differential regulation of the nodulation zone by silver ions, L- $\alpha$-(2-amino-ethoxyvinyl)-glycine, and the skl mutation in Medicago truncatula. Hayati Journal of Biosciences, 17(1), 15-20.

Prayitno, J., Imin, N., Rolfe, B. G., \& Mathesius, U. (2006). Identification of ethylene-mediated protein changes during nodulation in Medicago truncatula using proteome analysis. Journal of Proteome Research, 5(11), 3084-3095.

Prayitno, J., Rolfe, B. G., \& Mathesius, U. (2006b). The ethylene-insensitive sickle mutant of Medicago truncatula shows altered auxin transport regulation during nodulation. Plant Physiology, 142(1), 168-180.

Schmidt, J. S., Harper, J. E., Hoffman ,T. K., \& Bent, A. F. (1999). Regulation of soybean nodulation independent of ethylene signaling. Plant Physiology, 119(3), 951-960.

Standish, J. R., Brenneman, T. B., \& Stevenson, K. L. (2018). Dynamics of fungicide sensitivity in Venturia effusa and fungicide efficacy under field conditions. Plant Disease, 102(8), 1606-1611.
Suganuma, N., Yamauchi, H., \& Yamamoto, K. (1995). Enhanced production of ethylene by soybean roots after inoculation with Bradyrhizobium japonicum. Plant Science, 111(2), 163-168.

Tamimi, S. M., \& Timko, M. P. (2003). Effects of ethylene and inhibitors of ethylene synthesis and action on nodulation in common bean (Phaseolus vulgaris L.). Plant Soil, 257(1), 125-131.

Urao, T., Zamaguchi-Shinozaki, K., \& Shinozaki, K. (2000). Two-component systems in plant signal transduction. Trends in Plant Science, 5(2), 67-73.

van Zeijl, A., Op den Camp, R. H. M., Deinum, E. E., Charnikhova, T., Franssen, H., Op den Camp, H. J. M., Bouwmeester, H., Kohlen, W., Bisseling, T., \& Geurts, R. (2015). Rhizobium lipo-chitooligosaccharide signaling triggers accumulation of cytokinin in Medicago truncatula roots. Molecular Plant, 8(8), 1213-1226.

Wang, K. L., Li, H., \& Ecker, J. R. (2002). Ethylene biosynthesis and signaling networks. The Plant Cell, 12(1), 131-151.

Weller, J. L., Foo, E. M., Hecht, V., Ridge, S., Vander Schoor, J. K., \& Reid, J. B. (2015). Ethylene signaling influences light-regulated development in pea. Plant Physiology, 169(1), 115-124.

Xia, X., Ma, C., Dong, S., Xu, Y., \& Gong, Z. (2017). Effects of nitrogen concentrations on nodulation and nitrogenase activity in dual root systems of soybean plants. Soil Siences and Plant Nutrition, 63(5), 470-482. 